\title{
A Review of Application and Use of Dissimilar Metal Welding
}

Rohit Sahu and Ashish Srivastava

Department of Mechanical Engineering, G.L.Bajaj Institute of Technology \& Management (GLBITM), Greater Noida - 201306, Uttar Pradesh, India; rohit.sahu@glbitm.org, ashish.srivastava@glbitm.org

\begin{abstract}
Objective: This work aims to give a complete viewpoint of the nitty-gritty experiences with examinations and examination concerning novel weld joints. Methods/Statistical Analysis: This ongoing exploration gives a whole review of metallurgical properties of various weld joints, push/strain of the weld and arrangement of joint disillusionment of unique joints. Findings: It has been evaluated that most of the disillusionment has been connected with austenitic treated steel filler metal joints. It has been found that the joint structure - groove point - and weld quality interrelationship is considered by various people to be an immense variable. Application/Improvements: The sort of weld metal is of absolute centrality from the scattering and warm limitation perspectives.
\end{abstract}

Keywords: Dissimilar Metals, Steel, Welding

\section{Introduction}

The open creation surrenders an unobtrusively add to the image of the general subject with the subtleties of the metallurgical qualities of the interface zones between filler metal and base metal next to the range of the issues related with exceptional weld joints ${ }^{\underline{1}}$. The component of the issue with the association furthest reaches of headway joints has an alternate size contingent on one's vantage point. For instance, the general populations who need to supervise pure filler metals see and perceive fundamentally undeniably more great burdens than do the general population who need to treat the nickel-base filler metal exceptional joints. In the achievement of mechanical properties, all examinations saw equal parts paying little heed to how the components are given grouped trust in different cases.

\section{Literature Survey}

The ask for of utilization of different weld joints uncovered the standard made use out of austenitic filler metals by Krupp for covering steels. In the 1940s change, joints were made or potentially made for use in boilers ${ }^{2}$. These new joints were made with austenitic treated steel filler metals. In the 1950s and 1960s, there was an augmentation in the use of advancement joints for pot advantage, notably as steam temperatures rose to $1050^{\circ} \mathrm{F}\left(566^{\circ} \mathrm{C}\right)$. The 1970s and 1980s have seen increases in both the use and dissatisfaction occasions of progression joints 1 .

One of a kind metal welds is used in nuclear power plants and in oil refineries at zones where two particular sorts of materials, e.g., carbon steel and treated steel are joined. The nickel-base mix different metal welds usually are made of Alloy 182 and Alloy 82. Starting late, Alloy 52 has started to be used both in new improvements and infix welding 2. The part in Alloy 182 drives the example towards amalgams with higher proportions of chromium and starting late in like manner in Alloy 82. One driving force towards what are today acknowledged to be progressively protected amalgams is moreover the troubles and costs related to non-perilous examination of interesting metal welds ${ }^{3}$.

As the composing is scrutinized and the itemizing of frustration examinations noticed, various general substances create which most specialists can support from

*Author for correspondence 
their own experience. (It ought to be noted here that the vast majority of frustrations have been associated with austenitic tempered steel filler metal joints, and it is at present held by a few administrators that the disappointment mode with the nickel-base filler metals is on an incredibly important measurement not comparable to that with the perfect austenitic fillers). The general assurances are as indicated by the going with:

- Failures happen dependably in the HAZ of the ferritic piece neighboring the weld interface.

- The carbon-exhausted (touchy) zone in the low composite material is on a fundamental level ferrite and carbide. The carbon-upgraded (hard) zone may contain different constituents, yet carbides win.

- The ordinary course of action - groove point - and weld quality interrelationship is considered by different individuals to be a critical variable.

- Tensile properties of the weld and the base metals were unaltered from new material properties.

- The relative development coefficients of the distinct weldment areas are fundamental concerning warm weight age.

- PWHT adds to prior disappointments in both unadulterated and Ni-base filler metal change joints.

- Bending and vibration loads are surrendered to play a basic at any rate around depicted work. They may give light to the sensible variability of association life.

- The kind of weld metal is of certifiable criticalness from the dispersal and warm obstacle edges.

\section{Metallurgical Properties of Welds}

Welding opens up the probability to production expected stage multiplication and a game plan negative metallurgical change, for instance, delta ferrite arrange, grain limit erosion, strain utilization and sigma organize occurs at the welding interface. Consequently, expansive thought and safeguards like pre and post warm treatment or quick welding rates are required to make the extraordinary metallurgical properties ${ }^{4}$.

The little scale separation which occurs in weld mix zones of various metals prompts a situation where interdendritic districts are progressed in $\mathrm{Fe}, \mathrm{Cr}$ and $\mathrm{C}$. This disengagement inside the dendritic structure results in the rot of the mechanical properties and disintegration are deterrent of the joints.
Higher hardness at weld interface can be relied upon to advancement of this zone with $\mathrm{Fe}, \mathrm{Ni}$, and $\mathrm{Cr}$ and coming about the development of intermetallic $\mathrm{FeNi} / \mathrm{CrNiFe}$ arranges by Ni-based mixes ${ }^{5}$.

Unique weld of composite steel and treated steel, the sensitive zone jumped on the low compound steel can be ascribed to carbon utilization however improvement in the solidified steel side results prompts the advancement of hard and delicate carbide to organize a course of action. Chromium and nickel diffuse towards low compound steel from the solidified steel while press diffuses from low mix steel side towards tempered steel.

In the occasion of one of a kind weldment, the coefficients of warm improvement differ for base metal, weld and the scale. This refinement creates warm stresses in the midst of cooling which may impact grasp property of scale ${ }^{6}$.

Combination welding of one of kind steels has an issue that long holding up time which leads as far as possible utilization among grains and prone to be developed chrome-carbide hurry at $450-850^{\circ} \mathrm{c}$. Thus to avoid this, contact welding is commonly sensible.

\subsection{Stress/Strain State of Welds}

Part cannot occur without weight (strains), paying little regard to the microstructure just as its condition. For the part to occur, the strains constrained on the different microstructural zones by weldment loadings must outperform the strain strength of the microstructure in one of the districts. Usually simpler and more accommodating to discuss stresses. Nonetheless, by progress joints, it is likely logically huge to analyze the direct similarly as strain 4 .

The weights and strains conveyed with the creation and usage of interesting weld joints arise from:

- The difference being developed coefficients of the base metals and filler metals (with the best refinement being evident for perfect filler metals and ferritic base metals). Essential warming and cooling of joints with different coefficients produces tangential, longitudinal and winding components of push. The winding or shear component is the hardest to treat(especially if weld interface properties are unknown) and likely the most important concerning direct.

- Joint plan - in a general sense area or inclination edge controls shearing and distinctive tensions. Assessed advance joints moderate joint plan impacts, and what is more differential expansion stresses. 
- External winding weight and vibrational loadings are seen as essential anyway are difficult to review.

- Plastic stream occurs by killjoy to facilitate the constrained strains/stresses while the joint is at lifted temperature inciting a downer/exhaustion sort of mischief in the microstructure.

- The number of cycles and the events at the temperatures in the midst of cycling is necessary for the damage brought into the sensitive zone even without any external loadings.

- The last delayed consequence of the strain accommodation in the sensitive zone is cavitation and part.

\subsection{Methodology}

It should again be seen that in the vast majority of the failure the filler metal was austenitic tempered steel, and a couple of analysts exhibit that the mistake framework with the Ni-base filler metals may be different. The general accord concerning the arrangement of divergent metal joints disillusionment can be laid out as seeks after:

- The strain assembling in the carbon depleted lessened zone is quieted by drag at lifted temperature.

- The carbon-depleted fragile ferritic zone is constrained by the enveloping harder and more grounded material and is presented to strains actuated by:
a. Thermal development
b. Mismatch
c. Bending
d. vibration and weight

The game-plan of the carbon drained zone is the concealed improvement, and any treatment which invigorates the progression of this zone will overhaul disappointment likelihood. Creep hurt as cavitations, grain limit sliding and tearing outcomes to some extent in the carbon-exhausted delicate zone along and connecting the weld interface. The structure assessed joins the indication's of different administrators and may radiate an impression of being over-adjusted. In any case, complete operational data is precisely now and again accessible on fizzled change joints, and the metallurgical viewpoints are not through and through depicted. The refinement in thinking concerning the Ni-base filler metals fuses the decrease in the rate of enhancement of the carbon- drained zone and the foundation of to an incredible degree complex microstructure in the carbon-updated hard zone. Two or three administrators consider that the complex Microstructural constituents and their subordinate time strategy are the controlling variables in the Ni-base filler metal disappointment events. The image is less concerning Ni-base filler metal headway joints however ${ }^{6}$.

\section{Results}

As the idea of the disappointment wonder progressed toward becoming clearer (over time of years) strategies for limiting disappointments advanced. To counter against concerns, the accompanying contemplations have been referred to:

a. Closer match of extension coefficients in progress joint parts, i.e., Ni-base filler metals.

b. The utilization of "reviewed" progress joints or spool pieces which spread-out the coefficient of extension confound impact.

c. The utilization of settling buttering systems to limit carbon relocation.

d. Stabilization of the ferritic part with carbide formers to limit carbon relocation.

e. Elimination of Post Weld Heat Treatment (PWHT) which improves carbon relocation because of the temperatures utilized.

f. Joint design decision and upgraded control of weld quality.

\section{Conclusions}

The survey of the writing has uncovered zones in which inquire about and evaluation efforts should be attempted to all the more likely characterize the joint progress issue:

- Better documentation of frustrations and progressively concentrated dissatisfaction examination.

- Physical and mechanical property estimations of the zones at the interface including modulus, CTE, rigidity and creep break properties.

- Micro-structural concentrates to even more clearly portray the common interface including the "sensitive" carbon-depleted zone and the "hard" carbon-enhanced zone. 
- Stress examination work utilizing evaluated properties and encompassing the weight loosening up by killjoy in the midst of cycling.

- Better test frameworks are combining center stacking, bowing, depletion, and inside weight.

\section{References}

1. Devis MLE. How submerged arc flux composition influence element transfer. Weld. Pool Chemistry and Metall. The WI Cambridge, UK; 1980, 8. p. 289-310.

2. Chandel RS, Seon HP, Cheong FL. Effect of metal powder addition on mechanical properties of submerged arc welds, Journal of Materials Science. 1998; 1785-86.
3. Srivastava BK, Tewari SP, Prakash J. A review on Effect of arc welding parameter on the mechanical behavior of ferrous metals, International Journal of Engineering Science and Technology. 2010; 2(5):1425-32.

4. Karuna, Kirpala R, Singha H. Effect of Saw parameters on weld element transfer in SS316, International Journal of Current Engineering and Technology. 2011; 1:109-13.

5. Elsayed EA, Chen A. Optimal levels of process parameters for products with multiple Characteristics, International Journal production Research. 1993; 31(5):1117-32. https:// doi.org/10.1080/00207549308956778.

6. Myers R, Montgomery D. Response surface methodology. Wiley, New York, NY; 2009. p. 1-705. 